\title{
Family-to-work enrichment associations between family meal atmosphere and job satisfaction in dual-earner parents
}

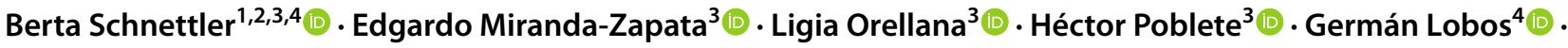 \\ María Lapo ${ }^{5}$ (C) Cristian Adasme-Berríos ${ }^{6}$ (1)
}

Accepted: 28 November 2021

(c) The Author(s), under exclusive licence to Springer Science+Business Media, LLC, part of Springer Nature 2021

\begin{abstract}
Research on factors related to job satisfaction in parents has mainly focused on work-related variables, paying less attention to family events that may provide parents with resources to invest in the work domain. To contribute to this body of knowledge, this study examined the associations between family meal atmosphere and job satisfaction in dual-earner parents with adolescent children, and tested the mediating role of family-to-work enrichment (FtoWE) between family meal atmosphere and job satisfaction. Questionnaires were administered to 473 different-gender dual-earner parents in Temuco, Chile. Participants answered the Project-EAT Atmosphere of family meals scale, three items that measure FWE from the Work-Home Interaction Survey, and the Overall Job Satisfaction Scale. Analyses were conducted using the Actor-Partner Interdependence Model and structural equation modelling. A positive association was found from family meal atmosphere to job satisfaction, directly and via FtoWE in fathers, and only via FtoWE in mothers. No associations were found for these variables between parents, as, one parent's perception of a pleasant family meal atmosphere is positively associated with their own FtoWE and job satisfaction, but not with those of the other parent. These findings suggest policymakers and organizations to account for workers' experiences in the family domain to improve satisfaction in the work domain.
\end{abstract}

Keywords family meals $\cdot$ resources $\cdot$ job satisfaction $\cdot$ enrichment $\cdot$ dual-earner couples $\cdot$ dyadic analysis

Berta Schnettler

berta.schnettler@ufrontera.cl

1 Facultad de Ciencias Agropecuarias y Forestales, Universidad de La Frontera, PO Box 54-D, Temuco, Chile

2 Scientific and Technological Bioresource Nucleus (BIOREN-UFRO), Universidad de La Frontera, Temuco, Chile

3 Universidad de La Frontera. Centro de Excelencia en Psicología Económica y del Consumo. Núcleo de Ciencias Sociales, Temuco, Chile

4 Facultad de Economía y Negocios, Universidad de Talca, Talca, Chile

5 Universidad Católica de Santiago de Guayaquil, Guayaquil, Ecuador

6 Departamento de Economía y Administración, Universidad Católica del Maule, Talca, Chile

\section{Introduction}

Research has identified job satisfaction as a positive outcome of the work-family interface (De Simone et al., 2014; Tang et al. 2014). Job satisfaction refers to the extent that workers like their job (Agho et al., 1992), and to the workers' perception of the levels of utilities and well-being that they derive from their work (Ferrada, 2017). Higher job satisfaction is associated with better performance at work, but also with well-being indicators outside the workplace, such as better health and higher life satisfaction (Chan et al., 2020). Moreover, the antecedents of job satisfaction are not only work-related, but also pertain to the family domain, as family demands can interfere with the individual's work role (Venkatesh et al., 2019), and as family resources can have a positive impact in the work domain (Kalliath et al., 2019). Thus, it becomes relevant to identify factors from the family domain that can help enrich the experiences in the work domain, including job satisfaction. In developing countries, research in this regard is more scarce than in developed countries (Montero \& Rau, 2015). As in other countries, 
in Chile, the number of dual-earner couples is increasing (Molina, 2021; Saieg, 2018), and uncovering family-to-work dynamics becomes a pressing issue to better understand the relationship between the work-family interface and wellbeing in workers and their families.

The determinants of job satisfaction have traditionally focused on workplace variables, for instance work conditions (e.g., Bahadur \& Shakil, 2021), workplace flexibility (e.g., Rhee et al., 2019), job insecurity (Emanuel et al., 2018), and colleagues, supervisor and organizational support (e.g., Kim et al., 2021; Paek et al., 2021; Yucel, 2020), among others. Nevertheless, research has also shown that variables from other life domains can also contribute to work outcomes, such as the family domain (ten Brummelhuis \& Bakker, 2012). The literature has given less attention to family-related antecedents of job satisfaction (Chan et al., 2020), but there is evidence indicating that family satisfaction (Emanuel et al., 2018; Schnettler et al., 2020a; Zhang et al., 2020) and family support (Chan et al., 2020; Lee \& Shin, 2017; Zhang et al., 2018) are positively related to job satisfaction. Therefore, identifying other family-related variables that may enhance worker's job satisfaction is important not only for workers, also for their families and for the organizations (Chan et al., 2020).

A relevant family dynamic among contemporary nuclear, dual-earner households is the family meal. In Latin America, family meals are considered a collective, structured foodrelated event (versus individual and unstructured food consumption) that provides socialization opportunities among family members (Riquelme \& Giacoman, 2018). Parents can be motivated to include family meals in the family routine as an opportunity to bond with their partner and children, expressing affection, sharing of values, communication and providing emotional support (Berge et al. 2018; Jones et al., 2018; Utter et al., 2018). Nevertheless, family meals can also entail conflict amongst family members (Riquelme \& Giacoman, 2018), and thus, positive or conflictive interactions among family members as they eat together may lead to different atmosphere of the family meals. Family meal atmosphere is understood as the quality of social environment during family meals, related to the degree of enjoyment, satisfaction and communication of family members with one another (Neumark-Sztainer et al., 2004).

The literature on this subject has focused on adolescents, and findings show that adolescents who have frequent family meals and perceive a positive mealtime atmosphere report greater emotional well-being (e.g., Berge et al., 2018; Jones, 2018; Utter et al., 2017; White et al., 2015). Less is known in this regard about the social and emotional benefits of family meals for their parents. Although recents studies have reported that family meals are associated with positive health and well-being outcomes, such as lower depression and higher self-esteem in parents (Utter et al., 2018; Giray \&
Ferguson, 2018), to the best of the authors' knowledge there are no published studies that have assessed the influence of family meal atmosphere on parents' positive outcomes in the job domain. Therefore, we raise the question of whether a pleasant family meal atmosphere can provide the worker with resources (i.e., social support, pleasant moods) that can be invested in their work domain, thus increasing their job satisfaction.

The personal resources that family meal atmosphere can provide to the individual (e.g., social support, positive moods) can be invested in the work domain, and they may be channeled via family-to-work enrichment (Wayne et al., 2020). The construct of work-family enrichment refers to the dynamics in which work can positively affect family (work-to-family enrichment), while family-to-work enrichment involve dynamics in which family can positively affect work (Greenhaus \& Powell, 2006; Tang et al., 2014). This study focuses on the latter, defined as a mechanism through which an individual transfers resources and experiences from the family domain to improve their performance in the workplace (Wayne et al., 2007). Most of the studies on work-family interface outcomes have focused on the effects of work-to-family enrichment on overall life satisfaction or domain satisfaction (Yucel, 2020), but there is evidence of a positive association between family support and familyto-work enrichment (Neneh, 2017; Siu et al., 2015; Wayne et al., 2020), and between family-to-work enrichment and job satisfaction (Kalliath et al., 2019; Yasir et al., 2019; Yucel, 2020). However, the intermediate role of FtoWE between family-related antecedents (i.e., family meal atmosphere) and job outcomes (i.e., job satisfaction) remains as an understudied issue in the work-family interface literature.

In addition, most of the previous studies have been carried out at an individual level, neglecting the interdependence and resource exchange between individuals (Yucel, 2020). A review on research regarding the work-family interface has indicated the need to focus more on the couple rather than on the individual, as well as the use of more sophisticated analytical approaches (Molina, 2021). Indeed, a fundamental assumption in behavioral and social science statistical methods is the independence of observations, but many of the phenomena studied in the work-family context are dyadic in nature (e.g., research on man-woman dyads, parent-child dyads). The observations arising from such designs are not independent, but interdependent (i.e., the characteristics of one member of the dyad affects outcomes of the other member in the dyad; Kenny et al., 2006; Ledermann et al., 2017). In this case, conventional statistical methods are not suitable for analysing data (such as regression, Kenny et al., 2006; Molina, 2021; Ledermann et al., 2017), and methods that consider the interdependence are required (Claxton et al., 2015; Kenny et al., 2006; Ledermann et al., 2017). This is an important distinction because the violations of 
the assumption of non-independence (i.e., when scores from two individuals are interrelated) can lead to biased parameter estimates and standard errors (Claxton et al., 2015; Ledermann et al., 2017). To address this issue, Kenny et al. (2006) developed the Actor Partner Interdependence Model (APIM). The APIM is the most frequently used analytical model of dyadic data (Garcia et al., 2015) because it simultaneously estimates the effects of an individual's attributes on their own outcome variable (actor effect), as well as their partner's (partner effect). The APIM has been used to investigate complex dynamics in family members and other close relationships, such as the association between parents' workfamily conflict and enrichment and their children's problem behaviours (Vieira et al., 2016), the relationship between couples' depression and relationship satisfaction ( $\mathrm{Li} \&$ Johnson, 2018), the link between parent and child experiences of parental work-family conflict (Morr \& Droser, 2020), the association between fathers' parenting uplifts and mothers' life satisfaction (Chen, 2020), and the relationship between parents' work-family conflict and enrichment and their adolescent children's well-being (Matias \& Recharte, 2021).

As the previous evidence shows, a dyadic analysis can uncover resource exchange through cross over in intimate partners, such as dual-earner parents. In this cross over processes each partner can respond to the other partners' resource gains as if it were their own (Hobfoll et al., 2018). This study thus proposes that the atmosphere of family meals and family-to-work enrichment may be vehicles of valuable resources for dual-earner parents; these resources may also be transmitted from one partner to the other and enhance both their job satisfaction.

Dual-earner parents also face specific demands from the family domain depending on their children's age. Childrelated variables, such as misbehavior (Venkatesh et al., 2019) can become stressors in the home that spill over to the parents' work domain, but it is expected that children who reach adolescence pose fewer demands to their parents than younger children (Tisdale \& Pitt-Catshupes, 2012). Nevertheless, the adolescent stage is also challenging for parents (Meier et al., 2018), and the parent-child dynamic can change radically. Compared to younger children, adolescents can both support and challenge their parents, on the one hand presenting them with resources to enhance family life (e.g., providing their parents emotional support or helping with domestic tasks), and on the other, posing demands (e.g. seeking independence; turning to risky behaviors, Borodovsky et al., 2021) that can generate strain in their parents. Some of these parent-child dynamics can manifest when family members get together, such as the family meals. Hence, the atmosphere of family meal in families with adolescents can be an indicator of the psychological resources that the family domain can provide to workers. These resources may then be invested in the work domain, manifesting not only in the individual's job satisfaction, but also in that of their partner who shares this home environment.

On this basis, this study tests the family-to-work relationships between family meal atmosphere and a positive work outcome (i.e., job satisfaction) in working mother-father dyads with adolescent children. The Work-home resources model (ten Brummelhuis \& Bakker, 2012) and the APIM (Kenny et al., 2006) provide the theoretical and empirical framework for this study. Therefore, the aim of this study is to examine the actor and partner effects between pleasant family meals and job satisfaction, with family-to-work enrichment as a mediating variable, in different-gender dualearner parents.

\section{Theoretical Framework}

Job satisfaction is determined by both objective (i.e., workplace conditions) and subjective (i.e., needs and expectations) factors from the work domain (Ferrada, 2017). Factors from other domains, such as family and home, can have an impact on job satisfaction. This family-to-work enrichment process can be explained by the work-home resources (W-HR) model (ten Brummelhuis \& Bakker, 2012). According to the W-HR model, enrichment occurs when resources from one domain help develop resources in another domain, which subsequently improve the performance in this second domain. Likewise, the resource-gain-development (RGD) perspective, proposed by Wayne et al. (2007), states that environmental resources, such as social support, promote different types of gains that enable enrichment. Moreover, these resources can be transmitted between members of a dyad, a process known as crossover, which can account not only for the individual's well-being, but also that of their closest relations (Hobfoll et al., 2018).

\section{Family Meal Atmosphere, Family to-Work Enrichment, and Job Satisfaction}

Family meals can be a resource pool for workers. Researchers have suggested that such resource pools (i.e., individual, work and family resources) can better equip individual employees to experience feelings of enrichment (Wayne et al., 2020). In this line of research, studies have found that family meals promote emotional well-being (Jones, 2018; White et al., 2015), and that family meals can provide a buffer for working parents. When parents can be present for family dinners, they may be able to work more hours without reporting feeling strained (Jones, 2018), and a higher frequency of family meals has been associated with greater family functioning and lower stress in mothers and fathers (Giray \& Ferguson, 2018; Utter et al., 2018). There are different aspects of family meal patterns (i.e., routines, rules). 
The focus of this study is the perception of the quality of the family meal atmosphere (Schnettler et al., 2018a), rather than as a fixed point in the family routine.

A pleasant family meal atmosphere entails the perception of positive experiences during communal mealtimes, in which family members enjoy this encounter and communicate with one another (Neumark-Sztainer et al., 2000). Enjoying shared meals and engagement in family communication during meals have positive effects on emotional health, because the voluntary exchange of information between family members provides emotional support to cope with psychological stressors (Giray \& Ferguson, 2018). Studies have reported that a positive family meal atmosphere can improve family relationships, such as family cohesion, parental involvement, communication, and perceived family support (Jones, 2018; Schnettler et al., 2018a). These experiences, in turn, can enhance family members' satisfaction with family life and life satisfaction (Schnettler et al., 2018a, Orellana et al., 2021b). A pleasant family meal atmosphere can be an occasion for family members to provide emotional support to the members in the work force; evidence shows that employees with higher family support report higher job performance and job satisfaction (Chan et al., 2020; Drummond et al., 2017; Lee \& Shin, 2017; Neneh, 2017).

Research has shown that family support is positively associated with family-to-work enrichment (Neneh, 2017; Siu et al., 2015; Wayne et al., 2020). We argue that family support expressed in interactions during family meals may provide workers with psychological resources, such as focused attention and energy, and it may foster positive moods (e.g., feelings of being cared about) that can spill over to the work domain, reducing work-related stress and enhancing psychological well-being, effectively producing family-to-work enrichment (Siu et al., 2015; Wayne et al., 2020). In addition, based on studies that have positively associated family-to-work enrichment with job satisfaction (Kalliath et al., 2019; Yasir et al., 2019; Yucel 2020), it was also expected that family-to-work enrichment would increase job satisfaction for both members of the couple. Thus, we posed the following hypotheses:

H1: (a) Mothers' and (b) fathers' atmosphere of family meal is positively related to job satisfaction (actor effects).

$\mathrm{H} 2$ : Atmosphere of family meal is positively related to family-to-work enrichment in (a) mothers and (b) fathers (actor effects).

H3: Family-to-work enrichment is positively related to job satisfaction for (a) mothers and (b) fathers (actor effects).

In keeping with the cross over processes in which partners exchange resources (Hobfoll et al., 2018), dyadic studies have shown that resources gained by dual-earner couples from the work-family interface can increase their partner's life satisfaction (Orellana et al., 2021a; Wayne et al., 2007). Examining family meals as a proxy for family support, we propose that the support experienced by one parent during family meals with a pleasant atmosphere may cross over to the other parent, providing the latter with resources that will, in turn, help increase their job satisfaction. Although no published evidence has been found of crossover involving family-to-work enrichment between members of a couple, it has been established that dual-earner parents' lives are interconnected and have common experiences and responsibilities in the home domain (ten Brummelhuis \& Bakker, 2012). Therefore, we argue that resources and positive experiences gained from the family domain by one parent may cross over to the other parent and help them improve their performance in the workplace, promoting enrichment in the receiving parent, which in turn will also increase their job satisfaction. We thus propose the following hypotheses:

H4: (a) Mothers' and (b) fathers' atmosphere of family meal is positively related to (a) fathers' and (b) mothers' job satisfaction (partner effects).

H5: (a) Mothers' and (b) fathers' atmosphere of family meal is positively related to (a) fathers' and (b) mothers' family-to-work enrichment (partner effects).

H6: (a) Mothers' and (b) fathers' family-to-work enrichment is positively related to job satisfaction for (a) fathers and (b) mothers (partner effects).

\section{Mediating Role of Work-to-Family Enrichment}

In this study, it is proposed that family-to-work enrichment has a mediating role between family-related variables and the job domain. This proposal is based on the W-HR model (ten Brummelhuis \& Bakker, 2012) and the RGD perspective (Wayne et al., 2007), which posit that environmental resources are key facilitators of enrichment, inasmuch they contribute to gains in one domain which enhance functioning in another domain (Wayne et al., 2007). Here, family meal atmosphere can be a key facilitator of family-to-work enrichment, which in turn may be associated with higher job satisfaction. Neneh (2017) has reported that family-towork enrichment mediates the relationship between emotional family support and firm performance among womenowned businesses, whereas Wayne et al. (2020) reported that supportive behaviours from family members are related to work-family balance satisfaction via an increased family-towork enrichment. In addition, there is evidence showing that family support has both a direct and an indirect effect on job satisfaction (Lee \& Shin, 2017).

Building on previous studies that have reported positive associations between family support and family-to-work 
enrichment (Neneh, 2017; Siu et al., 2015; Wayne et al., 2020), and between family-to-work enrichment and job satisfaction (Kalliath et al., 2019; Yasir et al., 2019; Yucel, 2020), we argue that, for parents, having a pleasant atmosphere at family meals may promote affective development that can facilitate functioning at the work domain, which in turn may enhance the individual's job satisfaction. Moreover, research has shown that when an individual reports enrichment from one domain to another, the enhancements may also manifest as gains for another member in the family system (e.g., in the marital dyad, Peeters et al., 2020; Wayne et al., 2007). Hence, we hypothesized that, in a mother-father dyad, family meal atmosphere and family-to-work enrichment of one parent could also increase the job satisfaction of the other parent. Therefore, the following hypotheses were posed:

H7: (a) Mothers' and (b) fathers' family-to-work enrichment significantly mediates the relationship between their own atmosphere of family meals and job satisfaction (actor effects)

H8: (a) Mothers' and (b) fathers' family-to-work enrichment significantly mediates the relationship between (a) fathers' and (b) mothers' atmosphere of family meals and job satisfaction (partner effects).

As it was previously mentioned, from a dyadic point of view, married or cohabiting couples also exchange resources through crossover processes (Hobfoll et al., 2018). However, these processes may vary by gender. Studies with differentgender couples have shown bidirectional or symmetrical crossover effects (from men to women, and from women to men) for some variables, and asymmetrical crossover effects for other variables (only from men to women, or only from women to men). For instance, Liu and Cheung (2015) found that work-to-family enrichment in women was positively associated with their husbands' life satisfaction, but not vice versa. By contrast, Orellana et al. (2021a) found that men's family support was positively associated with their female partner' work-life balance, but not vice versa. Schnettler et al. (2020a) found that men's life satisfaction was positively associated with their partner's satisfaction with family life, while women's life satisfaction was positively associated with their partner's satisfaction with family life and job satisfaction. Although in many countries the family and food domain are still predominantly considered women's labor associated with femininity and motherhood (e.g., Persson Osowski \& Mattsson Sydner, 2019; Saadat Abadi Nasab et al., 2021), this situation is more marked in Latin American countries such as Chile. Research in this country has reported that family meals constitute a gendered task, as women still carry the main responsibility of food-related chores, such as budgeting their food spending or the decisions made while planning what to eat and buy, shopping, and preparing meals (Cuevas et al., 2021; Rivera \& Giacoman, 2019; Schnettler et al., 2021b). Given these conditions, women with different-gender partners in Latin American cultures may find family mealtimes a daily stressful event: partnered women with a paid job are expected to take on most of the responsibilities in the home and family domain, in addition to their workload (Pagnan et al., 2017). Among the multiple responsibilities inside and outside the home, women are traditionally tasked with the responsibility of fixing family meals after coming home from work (Riquelme \& Giacoman, 2018; Rivera \& Giacoman, 2019). Therefore, as family meals are mainly considered a mother's task (Pagnan et al., 2017), asymmetrical partner effects may emerge between mothers and fathers, in terms of how much one partner's atmosphere of family meals affects the other partner's work-to-family enrichment and job satisfaction.

\section{Proposed Research Model}

The Actor-Partner Interdependence Model (APIM, Kenny et al., 2006) allows to explore the hypothesized associations between resources, stated as effects. In actor effects, the individuals' own characteristics predict their own outcomes; in partner effects, one member of the dyad's characteristics predict the outcomes for the other member (Kenny et al., 2006). The basic model for actor-partners effect is displayed in Figure 1. In this study, we propose that resources that an individual gains in daily family events can be transferred to improve their own experiences in the work domain, and these resources can also cross over to the individual's partner's work domain. Namely, we propose that the individual's perceived pleasant family meal atmosphere contributes to their own family-to-work enrichment and job satisfaction (actor effects), and to those of their partner (partner effects). We also propose that family-to-work enrichment is the mechanism that mediates the relationship between family meal atmosphere and job satisfaction, for both partners (Figure 2).

\section{Method}

\section{Sample and Procedure}

A sample of 473 different-gender dual-earner parents (married or cohabiting) with at least one adolescent child between 10 and 15 years of age was recruited through a convenience, non-probabilistic sampling in Temuco, Chile (Table 1). The World Health Organization defines adolescence as the period that spans from 10 to 19 years of age (WHO, 2014). However, in this study only families with children aged between 10 and 15 years were included, as 


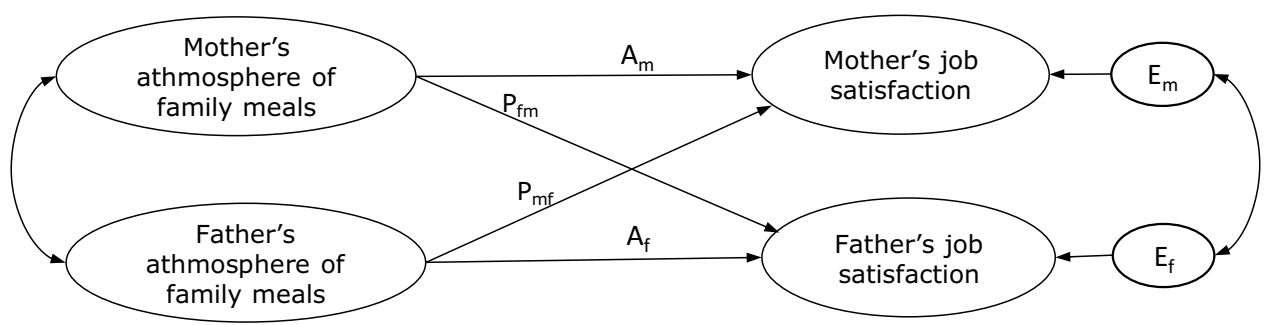

Fig. 1 Basic actor-partner interdependence model of atmosphere of family meals and job satisfaction. $\mathrm{A}_{\mathrm{m}}$ : actor effect of mother's atmosphere of family meals on her own job satisfaction; $A_{f}$ : actor effect of father's atmosphere of family meals on his own job satisfaction; $P_{f m}$ : partner effect of mother's atmosphere of family meals on man's job satisfaction; $\mathrm{P}_{\mathrm{mf}}$ : partner effect of father's atmosphere of family meals on mother's job satisfaction; $E_{m}$ and $E_{f}$ : residual errors on satisfaction for the mother and father, respectively
Fig. 2 Conceptual model of the proposed actor and partner effects between atmosphere of Family Meals (AFM), Family-to-Work Enrichment (FtoWE) and Job Satisfaction (OJSS) in dual-earner parents with adolescent children. Black arrows indicate direct effects, grey arrows indicate indirect effects. Em and Ef: residual errors on OJJS for the mothers and fathers, respectively

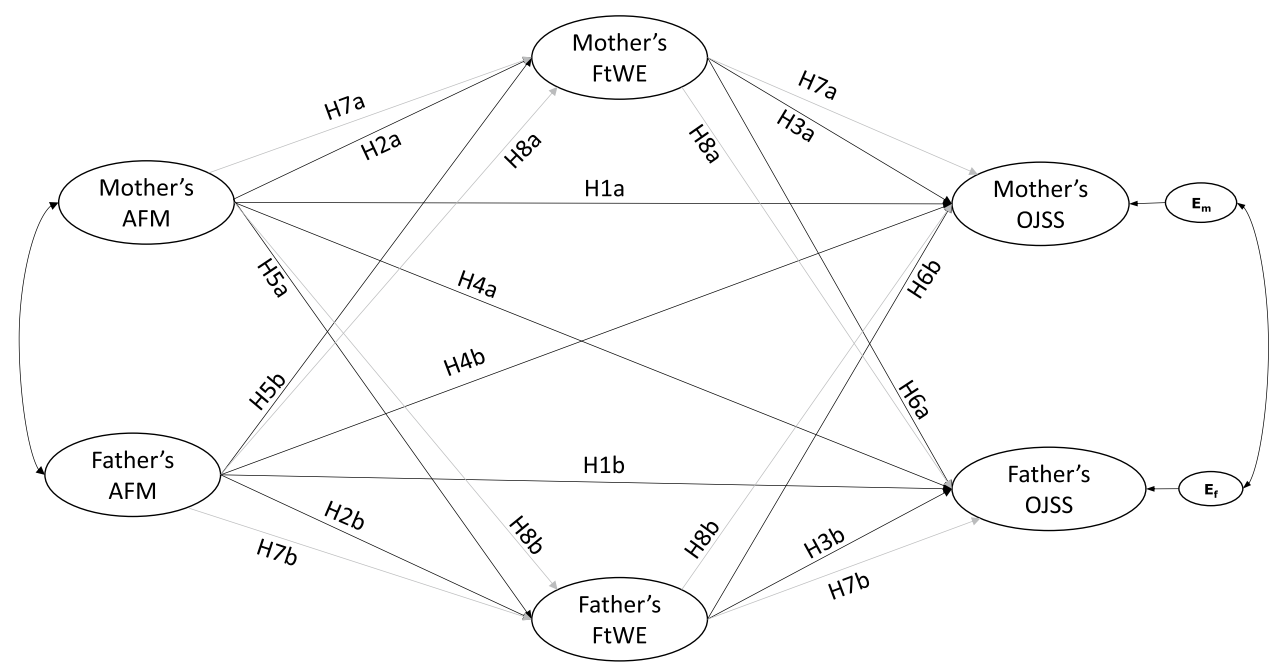

they are still highly influenced by their family's eating habits (Schnettler et al., 2021b). Families were recruited in seven schools located in the urban area of the city, and which served socioeconomically diverse populations, to include socioeconomically diverse dual-earner parents in the sample. Directors from each school signed authorization letters to conduct the research with their students. Parents were contacted via the schools with an invitation to participate in this study, providing the following information: Aims of the study, sample criteria, the questionnaire structure and data collection procedure (see below), and the anonymous and confidential treatment of the data. This invitation was sent to parents of children from fifth grade of primary (corresponding to a minimum age of 10 years) to the first grade of secondary level (corresponding to a maximum age of 15 years). This study is part of a broader research that examines interrelations between job and family domains and eating habits in Chilean families.

Parents who agreed to participate provided their telephone numbers. Trained interviewers called those parents to agree on the date and time for the application of the surveys, then they were visited in their homes by the trained interviewers. The interviewers provided information about the study's aims and guaranteed confidentiality of their data, and the questionnaire's structure; this information was also presented to potential participants during recruitment. Both parents signed informed consent forms, and the interviewer administered the questionnaire to each parent separately. Data was collected between August and December 2019, and responses were recorded by the interviewers in the QuestionPro (QuestionPro Inc) platform. After responding the questionnaires, parents received a gift card worth approximately 15 USD. A pilot test was conducted with 20 families following the same procedure described above; the results were deemed satisfactory, and no changes were required for the data collection process nor in the questionnaires. This study was approved by the Ethics Committee of [information has been removed for masked review].

\section{Measures}

The following instruments were answered by both members of the couple: 
Table 1 Sample characteristics $(n=473)$

\begin{tabular}{|c|c|c|}
\hline Characteristic & Total sample & P-value ${ }^{1}$ \\
\hline \multicolumn{3}{|l|}{ Age $[\text { Mean }(S D) \text { (range) }]^{1}$} \\
\hline Mother & $\begin{array}{l}39.1(7.2)(22- \\
60)\end{array}$ & $<.001$ \\
\hline Father & $\begin{array}{l}42.0(8.9)(20- \\
70)\end{array}$ & \\
\hline Number of family members [Mean $(S D)$ (range)] & $4.4(1.0)(3-10)$ & \\
\hline Number of children [Mean $(S D)$ (range)] & $2.2(0.8)(1-6)$ & \\
\hline \multicolumn{3}{|l|}{ Socioeconomic status (\%) } \\
\hline High & 22.2 & \\
\hline Middle & 61.5 & \\
\hline Low & 16.3 & \\
\hline \multicolumn{3}{|l|}{ Gender of the main breadwinner (\%) } \\
\hline Female & 23.3 & \\
\hline Male & 76.7 & \\
\hline \multicolumn{3}{|c|}{ Number of days/week couples ate together [Mean $(S D)$ (range)] } \\
\hline Breakfast & $2.8(2.3)(1-7)$ & \\
\hline Lunch & $3.3(2.2)(1-7)$ & \\
\hline Supper & $5.1(2.5)(1-7)$ & \\
\hline Dinner & $2.5(3.1)(1-7)$ & \\
\hline \multicolumn{3}{|c|}{ Number of hours per day spent cooking during the week $[\text { Mean (SD) (range) }]^{1}$} \\
\hline Mother & $2.2(1.3)(1-5)$ & $<.001$ \\
\hline Father & $1.0(1.3)(0-3)$ & \\
\hline \multicolumn{3}{|c|}{ Number of hours per day spent cooking on the weekend [Mean (SD) (range)] $]^{1}$} \\
\hline Mother & $3.0(1.7)(1-6)$ & $<.001$ \\
\hline Father & $1.6(1.5)(0-2)$ & \\
\hline \multicolumn{3}{|l|}{ Type of employment $(\%)^{2}$} \\
\hline Woman employee & 72.7 & .46 \\
\hline Woman self-employed & 27.3 & \\
\hline Man employee & 74.8 & \\
\hline Man self-employed & 25.2 & \\
\hline \multicolumn{3}{|l|}{ Working hours $(\%)^{2}$} \\
\hline Woman working 45 hours per week & 59.2 & $<.001$ \\
\hline Woman less than 45 hours per week & 40.8 & \\
\hline Man working 45 hours per week & 72.3 & \\
\hline Man working less than 45 hours per week & 27.7 & \\
\hline
\end{tabular}

To measure the atmosphere of family meals the ProjectEAT Atmosphere of family meals (AFM, Neumark-Sztainer et al., 2000, 2004) was used. Four items assessed mealtime atmosphere: two items related to enjoyment of mealtimes ("I enjoy eating meals with my family" and "In my family, eating brings people together in an enjoyable way") whereas two items tapped mealtime communication (e.g., "In my family, mealtime is a time for talking with other family members" and "In my family, dinner/supper time is about more than just getting food, we all talk with each other"). The AFM showed a good internal consistency in a study conducted in the United Kingdom (White et al., 2015).
The Spanish version of the AFM scale was used (Schnettler et al., 2018b). In the last item, a traditional Chilean evening meal equivalent to supper was included as an alternative to dinner, as in this country this meal is routinely shared with others instead of dinner. Respondents indicated their degree of agreement with each statement using a 6-point Likert scale (1: completely disagree; 6: completely agree). Mean scores were calculated with higher scores representing a more positive mealtime atmosphere. In the present study, the standardised factor loadings of the FMA scale ranged from .802 to .937 for mothers and from .777 to .918 for fathers, all statistically significant $(\mathrm{p}<.01)$. The average 
extracted variance (AVE) values were higher than .50 (AVE mothers $=.77$, fathers $=.73$ ) . The AFM scale showed good internal reliability, with Omega coefficients of .93 for mothers and .91 for fathers.

To measure job satisfaction, the Overall Job Satisfaction Scale (OJSS) was used. This scale comprises six items selected by Agho et al. (1992, e.g., "I find real enjoyment in my job") out of the 18-item index developed by Brayfield and Rothe (1951). Research in different countries shows that the OJSS has good internal consistency (Agho et al., 1992; Lee et al., 2014). The validated Spanish version of the OJSS scale was used (Schnettler et al., 2020a). Respondents indicated their degree of agreement with each statement using a 5-point Likert scale (1: completely disagree; 5: completely agree). OJSS scores were obtained via a sum of the scores from the six items, with higher scores representing a greater job satisfaction. In the present study, the standardized factor loadings of the OJSS scale ranged from .480 to .924 for mothers and from .553 to .917 for fathers, all statistically significant $(\mathrm{p}<.01)$. The AVE values were higher than .50 $($ AVE mothers $=.65$, fathers $=.62)$. The OJJS scale showed good internal reliability, with Omega coefficients of .92 for mothers and .91 for fathers.

To measure family-to-work enrichment, three items based on Nijmegen's Work-Home Interaction Survey (SWING; Wagena \& Geurts, 2000) were used (i.e., "After spending time with your spouse/family, do you go to work in a good mood, positively affecting the atmosphere at work?", "Do you take your responsibilities at work more seriously because you are required to do the same at home?", "Do you manage your time at work more efficiently because at home you have to do that as well?"). The family-to-work enrichment measure showed a good internal consistency in a study conducted in Italy (De Simone et al., 2014). The Spanish version this measure was used (Schnettler et al., 2018b). Each item was responded on a 5-point scale (1: never; 5: very often). In the present study, the standardized factor loadings of the family-to-work enrichment measure ranged from .756 to .863 for mothers and from .691 to .903 for fathers, all statistically significant $(\mathrm{p}<.01)$. The average extracted variance (AVE) values were higher than .50 (AVE mothers $=.68$, fathers $=.60)$. The family-to-work enrichment dimension showed good internal reliability, with Omega coefficients of .86 for mothers and .82 for fathers.

Both members of the couple were asked about their age, type of employment, and the number of working hours per week. Women were asked about the number of family members, the number of children, the gender of the parent with the highest income, the number of days that all family members eat together during the week (breakfast, lunch, supper, and dinner), and the number of hours per day that they and their male partner spend cooking during the week and on weekend. The family socioeconomic status (SES) was determined based on the total household income and its size (AIM, 2016).

\section{Data Analysis}

Descriptive analyses were conducted using SPSS v.23. Common method variance (CMV, Chang et al., 2010) was examined prior to hypothesis testing, conducting Harman's single-factor test for each parent separately. All items from the measured constructs -Project-EAT Atmosphere of family meals, family-to-work enrichment measure, and the Overall Job Satisfaction Scale- were loaded into a factor analysis. This procedure allowed to check whether one single factor emerged or whether more factors are detected and one of them leads to the majority of the covariance among these three measures. CMV is considered of no concern in the study if no single factor emerges and accounts for majority of the covariance (Chang et al., 2010). This test was conducted using principal component analysis (PCA) without rotation in SPSS.

To test the actor and partner effects between the atmosphere of family meals (AFM), family-to-work enrichment (FtoWE), and job satisfaction (OJJS), the actor-partner interdependence model (APIM) with distinguishable dyads was assessed using structural equation modelling (SEM, Kenny et al., 2006). The unit of analysis for the APIM is the dyadic interaction, and each dyad member is both an actor and a partner in the analysis (Kenny et al., 2006). Actor effects refer to the associations between the AFM of one member of the dyad with their own FtoWE and OJJS, and between this member's FtoWE and their own OJJS. Partner effects refer to the associations between the AFM of one member of the dyad with the FtoWE and OJJS of the other member, and between the FtoWE of one member of the dyad with the OJJS of the other member.

The APIM controls for the mutual effect of AFM from one member of the dyad to the other by showing correlations between both members' independent variables (i.e., the mother's and the father's AFM). Other sources of interdependence between partners are also controlled for by including correlations between the residual errors of the dependent variables of each dyad member (i.e., the mother's OJSS and the father's OJSS, Kenny et al., 2006).

Variables with direct effects on the outcomes of both members of the dyad (FtoWE and OJSS) were incorporated to control for in modelling the fit of the data. The following variables were controlled for: both dyad members' age, the number of children, type of employment and number of working hours; the family SES, and the number of times per week in which all family members had supper together. Age of both parents was introduced as a control variable because previous studies have shown a positive relationship between age and job satisfaction (Dobrow Riza et al., 2018). Number 
of children was also included, as the literature has shown its influence on the relationship between family-to-work enrichment and work-related outcomes (Zhang et al., 2018). Type of employment and the number of working hours were included as control variables due to the evidence showing that those self-employed experience higher job satisfaction than employees (Janicijevic \& Paunović, 2019), while working part-time positively influences the mother's job satisfaction (Bridges \& Owens, 2017). The family SES was incorporated as lower income has been related to lower job satisfaction ( $\mathrm{Li}$ et al., 2020). Although there is no evidence regarding the influence of the frequency of family meals on job satisfaction, times per week in which all family members had supper together were included as a control variable as it has been shown that an increasing frequency of family meals is associated with positive outcomes in mothers and fathers (Utter et al., 2018).

SEM was conducted using Mplus 7.11. The robust unweighted least squares (ULSMV) were used to estimate structural model parameters. The SEM analysis was done via the polychoric correlation matrix, given the ordinal scale of the items. The model fit of the data were determined using the Tucker-Lewis index (TLI), the comparative fit index (CFI) and the root mean square error of approximation (RMSEA). The TLI and CFI presents a good fit when values are above .95 . For the RMSEA, a good fit is defined by values below .06 (Hu \& Bentler, 1999; Marsh et al., 2005).

To test the mediating roles of FtoWE, a SEM through a bias-corrected (BC) bootstrap confidence interval was used with 1,000 samples (Lau \& Cheung, 2012). Support for a mediating role was found when the $\mathrm{BC}$ confidence interval for the mediation effect did not include zero.

\section{Results}

\section{Sample Description}

The sociodemographic characteristics of the sample are shown in Table 1. The sample consisted of 473 different-sex dual-earner parents; the mean age for mothers was 39.1 years, and for fathers, 42 years. Men were significantly older than women $(\mathrm{p}<.001)$. The mothers reported an average of four family members and two children. Most couples were in a middle SES and reported that the father earned the highest income in the household. The average number of days per week in which both members of the couple ate together breakfast, lunch, and dinner were between two and three, whereas for supper this number increased to five days. Mothers cooked for a significantly higher average of hours per day during the week and on weekends than their male partners $(\mathrm{p}<.001)$. Most participants were dependent workers (i.e., employees) and worked 45 hours per week (a full-time job in Chile). There was a greater proportion of participants who worked 45 hours per week among fathers, compared to mothers $(\mathrm{p}<.001)$. There was no difference between mothers and fathers in the proportions of employees and self-employed $(\mathrm{p}>.1)$.

Following the Harman's single-factor test, the generated PCA output for the three measures used in this study revealed three distinct factors for each parent, accounting for $68.9 \%$ and $65.5 \%$ of the total variance for mothers and fathers, respectively. The first unrotated factor captured only $34.9 \%$ and $33.9 \%$ of the variance in data for mothers and fathers, respectively. Overall, no single factor emerged, and the first factor did not capture most of the variance in mothers and fathers, and hence CVM appears to be not an issue in this study (Chang et al., 2010).

Table 2 shows the average scores and the correlations for the variables included in the present study. Mothers and fathers did not differ in the average scores on the atmosphere of family meals (AFM, $\mathrm{p}=.063)$, FtoWE $(\mathrm{p}=.094)$ nor in the OJJS scale $(\mathrm{p}=.540)$. Mothers' and fathers' ATM, FtoWE and OJJS were positively associated with each other $(\mathrm{p}<.01)$. Mothers' ATM correlated positively with their own FtoWE and OJJS ( $\mathrm{p}<.01)$ as well as with the fathers' FtoWE $(\mathrm{p}<.01)$ and OJJS $(\mathrm{p}<.05)$. Fathers' ATM correlated positively with their own FtoWE and OJJS $(\mathrm{p}<.01)$ as well as with the mothers' FtoWE $(\mathrm{p}<.05)$ and OJJS $(\mathrm{p}<.01)$. Mothers' FtoWE correlated positively with their
Table 2 Descriptive statistics and correlations for Atmosphere of Family Meals (AFM), Family-to-Work Enrichment (FtoWE), and Job Satisfaction (OJJS) in different-sex dualearner couples $(n=473)$

\begin{tabular}{llllllll}
\hline & M (SD) & \multicolumn{2}{l}{ Correlations } \\
\cline { 3 - 7 } & & 1 & 2 & 3 & 4 & 5 & 6 \\
\hline 1. Mothers' AFM & $5.4(.8)$ & 1 & $.43^{* *}$ & $.26^{* *}$ & $.22^{* *}$ & $.17^{* *}$ & $.10^{* *}$ \\
2. Fathers' AFM & $5.3(.9)$ & & 1 & $.09^{*}$ & $.29^{* *}$ & $.13^{* *}$ & $.17^{* *}$ \\
3. Mothers' FtoWE & $12.5(2.5)$ & & & 1 & $.24^{* *}$ & $.24^{* *}$ & .07 \\
4. Fathers' FtoWE & $12.2(2.5)$ & & & & 1 & $.13^{* *}$ & $.27^{* *}$ \\
5. Mothers' OJJS & $22.3(4.8)$ & & & & & 1 & $.25^{* *}$ \\
6. Fathers' OJJS & $22.4(5.0)$ & & & & & & 1 \\
\hline
\end{tabular}

* Correlation is significant at the .05 level (2-tailed)

** Correlation is significant at the .01 level (2-tailed) 
own OJJS ( $p<.01$ ), but not with the fathers' OJJS ( $p>.1$ ), whereas fathers' FtoWE correlated positively with their own OJJS $(\mathrm{p}<.01)$ as well as with the mothers' OJJS $(\mathrm{p}<.01)$.

\section{APIM Results: Testing Actor-Partner Hypotheses}

The results from the estimation of the structural model are shown in Figure 3 (direct relationships). The model that assessed the APIM association between the mothers' and fathers' atmosphere of family meals and their levels of FtoWE and job satisfaction had a good fit with the data $(\mathrm{CFI}=.967 ; \mathrm{TLI}=.961 ; \mathrm{RMSEA}=.020)$. A significant correlation (covariance) was found between the atmosphere of family meals score of both members of the dyad $(r=$ $.505, \mathrm{p}<.001)$ as well as between the residual errors of mother's and father's job satisfaction $(\mathrm{r}=.234, \mathrm{p}<.001)$.

Most of the control variables did not affect the model significantly (Table 3 ). The fathers' type of employment (employee vs self-employed) negatively affected the mothers' FtoWE $(\gamma=-.123, p<.05)$, i.e., mothers with a selfemployed partner had lower levels of FtoWE than mothers with an employed partner. The number of supper times per week in which the couple ate together positively affected the mothers' $(\gamma=.113, \mathrm{p}<.05)$ and fathers' FtoWE $(\gamma=$ $.122, \mathrm{p}<.05)$. The type of employment (employee vs selfemployed) positively affected mothers' $(\gamma=.124, \mathrm{p}<.05)$ and fathers' job satisfaction $(\gamma=.114, \mathrm{p}<.05)$, i.e., selfemployed mothers and fathers had higher levels of job satisfaction than employed mothers and fathers. The fathers' age also positively affected their own job satisfaction $(\gamma=$ $.264, \mathrm{p}<.001)$, and a similar effect was found for family $\operatorname{SES}(\gamma=.148, p<.01)$, i.e., those fathers belonging to the high SES experience higher level of job satisfaction than those of lower SES.

\section{Actor Effects}

H1 stated that the atmosphere of family meals is positively related to job satisfaction in mothers (H1a) and fathers (H2a). As shown in Figure 3, the path coefficients (standardized) indicate that the mothers' atmosphere of family meals was not significantly associated with their own job satisfaction $(\gamma=.067, \mathrm{p}=.305)$. By contrast, the fathers' atmosphere of family meals was positively and significantly associated with their own job satisfaction $(\gamma=.144, p=$ .032). These findings did not support H1a while they supported $\mathrm{H} 1 \mathrm{~b}$.

The second hypothesis stated that atmosphere of family meal is positively related to family-to-work enrichment in mothers (H2a) and fathers (H2b). Atmosphere of family meals was positively associated with FtoWE in mothers $(\gamma=$ $.410, \mathrm{p}<.001)$ and fathers $(\gamma=.396, \mathrm{p}<.001)$, supporting both $\mathrm{H} 2 \mathrm{a}$ and $\mathrm{H} 2 \mathrm{~b}$.

The third hypothesis stated that family-to-work enrichment is positively related to job satisfaction for mothers (H3a) and fathers (H3b). Results show that FtoWE was positively associated with their own job satisfaction for mothers $(\gamma=.317, \mathrm{p}<.001)$ and fathers $(\gamma=.336, \mathrm{p}<.001)$. These findings supported $\mathrm{H} 3 \mathrm{a}$ and $\mathrm{H} 3 \mathrm{~b}$.

\section{Partner Effects}

The first hypothesis testing partner effects stated that mothers' atmosphere of family meals is positively related to the

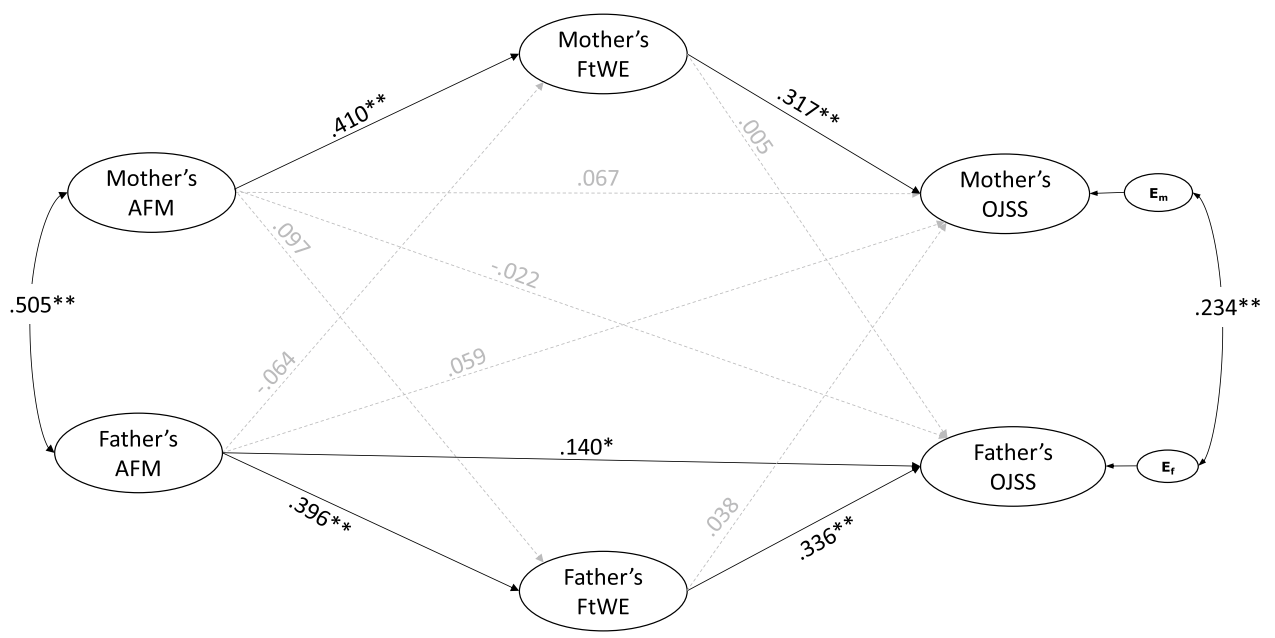

Fig. 3 Actor-partner interdependence model of the effect Atmosphere of Family Meals (AFM) on Family-to-Work Enrichment (FtoWE) and Job Satisfaction (OJSS) in dual-earner parents with adolescent children. $\mathrm{E}_{\mathrm{m}}$ and $\mathrm{E}_{\mathrm{f}}$ : residual errors on OJJS for the mothers and fathers, respectively. $* p<.05 * * p<.01$. The control for the effects both members of the couple' age, type of employment and their number of working hours as well as the family SES, the number of children and the number of supper in which all the family members ate together during a week on the dependent variable of both members of the couple (OJSS) are not shown in the path diagram 
Table 3 Standardized effect estimates of control variables on Family-to-Work Enrichment (FtoWE) and on Job Satisfaction (OJJS) in dualearner couples

\begin{tabular}{|c|c|c|}
\hline & Estimate & p-value \\
\hline Mother's age $\rightarrow$ Mother's FtoWE. & -.02 & .79 \\
\hline Mother's type of employment $\rightarrow$ Mother's FtoWE & -.03 & 62 \\
\hline Mother's working hours $\rightarrow$ Mother's FtoWE & -.06 & .25 \\
\hline Father's age $\rightarrow$ Mother's FtoWE & .08 & .31 \\
\hline Father's type of employment $\rightarrow$ Mother's FtoWE & -.12 & $.04 *$ \\
\hline Father's working hours $\rightarrow$ Mother's FtoWE & .05 & .33 \\
\hline Family socioeconomic status $\rightarrow$ Mother's FtoWE & .03 & .56 \\
\hline Number of children $\rightarrow$ Mother's FtoWE & .03 & .50 \\
\hline Number of supper meals per week ate together $\rightarrow$ Mother's FtoWE & .11 & $.04 *$ \\
\hline Mother's age $\rightarrow$ Father's FtoWE & .01 & .86 \\
\hline Mother's type of employment $\rightarrow$ Father's FtoWE & -.06 & .28 \\
\hline Mother's working hours $\rightarrow$ Father's FtoWE & -.01 & .77 \\
\hline Father's age $\rightarrow$ Father's FtoWE & -.03 & 63 \\
\hline Father's type of employment $\rightarrow$ Father's FtoWE & -.09 & .12 \\
\hline Father's working hours $\rightarrow$ Father's FtoWE & .08 & .17 \\
\hline Family socioeconomic status $\rightarrow$ Father's FtoWE & -.07 & .20 \\
\hline Number of children $\rightarrow$ Father's FtoWE & .01 & .73 \\
\hline Number of supper meals per week ate together $\rightarrow$ Father's FtoWE & .12 & $.02 *$ \\
\hline Mother's age $\rightarrow$ Mother's OJJS & .10 & .10 \\
\hline Mother's type of employment $\rightarrow$ Mother's OJJS & .12 & $.02 *$ \\
\hline Mother's working hours $\rightarrow$ Mother's OJJS & -.05 & .36 \\
\hline Father's age $\rightarrow$ Mother's OJJS & .01 & .81 \\
\hline Father's type of employment $\rightarrow$ Mother's OJJS & -.04 & .43 \\
\hline Father's working hours $\rightarrow$ Mother's OJJS & .06 & .21 \\
\hline Family socioeconomic status $\rightarrow$ Mother's OJJS & -.09 & .07 \\
\hline Number of children $\rightarrow$ Mother's OJJS & .04 & .36 \\
\hline Number of supper meals per week ate together $\rightarrow$ Mother's OJJS & .03 & .43 \\
\hline Mother's age $\rightarrow$ Father's OJJS & -.08 & .19 \\
\hline Mother's type of employment $\rightarrow$ Father's OJJS & .07 & .17 \\
\hline Mother's working hours $\rightarrow$ Father's OJJS & -.01 & .81 \\
\hline Father's age $\rightarrow$ Father's OJJS & .26 & $<.001 * *$ \\
\hline Father's type of employment $\rightarrow$ Father's OJJS & .11 & $.02 *$ \\
\hline Father's working hours $\rightarrow$ Father's OJJS & .01 & .78 \\
\hline Family socioeconomic status $\rightarrow$ Father's OJJS & .14 & $.004 * *$ \\
\hline Number of children $\rightarrow$ Father's OJJS & .01 & .74 \\
\hline Number of supper meals per week ate together $\rightarrow$ Father's OJJS & .02 & .53 \\
\hline
\end{tabular}

$* p<.05$

$* * p<.01$ fathers' job satisfaction ( $\mathrm{H} 4 \mathrm{a})$, and that fathers' atmosphere of family meals is positively related to the mothers' job satisfaction (H4b). As shown in Figure 3, mothers' atmosphere of family meals was not statistically associated with the fathers' job satisfaction $(\gamma=-.022, p=.732)$. Likewise, the fathers' atmosphere of family meals was not statistically associated with the mothers' job satisfaction $(\gamma=.059, \mathrm{p}=.380)$. Thus, these findings did not support H4a nor H4b.

The second hypothesis testing partner effects stated that mothers' atmosphere of family meals is positively related to the fathers' family-to-work enrichment (H5a), and that fathers' atmosphere of family meals is positively related to the mothers' family-to-work enrichment (H5b). Results show that the mothers' atmosphere of family meals was not significantly associated with the fathers' FtoWE $(\gamma=.097$, $\mathrm{p}=.127$ ), nor the fathers' atmosphere of family meals was significantly associated with the mothers' FtoWE $(\gamma=-.064$, $\mathrm{p}=.353$ ). Therefore, these findings did not support H5a nor H5b.

The third hypothesis testing partner effects stated that mothers' family-to-work enrichment is positively related to job satisfaction for fathers (H6a), and that fathers' 
family-to-work enrichment is positively related to job satisfaction for mothers (H6b). As shown in Figure 3, mothers' FtoWE was not significantly associated with the fathers' job satisfaction $(\gamma=.005, p=.926)$, and, likewise, the fathers' FtoWE was not significantly associated with the mother's job satisfaction $(\gamma=.038, \mathrm{p}=.549)$. These findings did not support H6a nor H6b.

\section{Testing Mediating Roles of Family-to-Work Enrichment}

The first hypothesis testing the mediating role of FtoWE stated that mothers' family-to-work enrichment mediates the relationship between their own atmosphere of family meals and job satisfaction (H7a) and that fathers' family-to-work enrichment mediate the relationship between their own atmosphere of family meals and job satisfaction (H7b). The role of the mothers' FtoWE as mediator in the relationship between their own atmosphere of family meals and job satisfaction was supported by a significant indirect effect obtained with the bootstrapping confidence interval procedure (standardized indirect effect $=$ $.130,95 \% \mathrm{CI}=.036, .162$ ), as the confidence intervals did not include zero. Likewise, the role of the fathers' FtoWE as a mediator in the relationship between their own atmosphere of family meals and job satisfaction was supported, given that the confidence interval did not include zero (standardized indirect effect $=.133,95 \% \mathrm{CI}=.073, .234)$. Therefore, these findings supported $\mathrm{H} 7 \mathrm{a}$ and $\mathrm{H} 7 \mathrm{~b}$.

The second hypothesis testing the mediating role of FtoWE stated that mothers' family-to-work enrichment significantly mediates the relationship between the fathers' atmosphere of family meals and job satisfaction (H8a), and that fathers' family-to-work enrichment significantly mediates the relationship between the mothers' atmosphere of family meals and job satisfaction (H8b). The indirect effect of the mothers' FtoWE as mediator in the relationship between the fathers' atmosphere of family meals and job satisfaction was not supported as the confidence intervals did include zero (standardized indirect effect $=.000,95 \%$ $\mathrm{CI}=-.009, .008)$. Similarly, the indirect effect of the fathers' FtoWE as mediator in the relationship between the mothers' atmosphere of family meals and job satisfaction was not supported as the confidence intervals did include zero (standardized indirect effect $=.004,95 \% \mathrm{CI}=-.007, .013)$. These findings thus did not support H8a nor H8b. This role is found for actor, but not for partner effects.

\section{Discussion}

There is emerging research in developing countries, such as Chile, regarding the determinants of job satisfaction (e.g., Montero \& Rau, 2015). These determinants can be objective (i.e., work conditions) or subjective (i.e., expectations, Ferrada, 2017). This study contributes to this line of research by expanding the scope of these determinants, looking beyond work conditions and including perceptions and experiences derived from the work-family interface. Namely, this study explored the transmission of resources from the family to the work domain between working parents, by testing the associations between family meal atmosphere, family-towork enrichment (FtoWE), and job satisfaction in differentgender dual-earner parents with adolescent children. Using the APIM approach, eight hypotheses were tested, related to actor effects (H1-H3), partner effects (H4-H6), and the mediating role of family-to-work enrichment between family meal atmosphere and job satisfaction (H7 and H8) for both parents.

This study contributes to the work-family interface literature by showing that family-to-work enrichment is a mechanism that helps explain the link between the quality of daily family events, in this case, family meals, and positive outcomes in the job domain. Specifically, this study showed a positive association from family meal atmosphere to job satisfaction, directly and via FtoWE in fathers, whereas in mothers the positive association from family meal atmosphere to job satisfaction was only via FtoWE. The direct effect from family meal atmosphere to job satisfaction in fathers, as well as its indirect effects via FtoWE in both parents were of low strength, following Cohen (1988), whereas the direct effects from family meal atmosphere to FtoWE and from FtoWE to job satisfaction were of medium strength in both parents. These findings are discussed in detail below.

\section{Actor Effects}

For the first set of hypotheses, actor effects were found from family meal atmosphere to job satisfaction only in fathers (H1b), and from family meal atmosphere to FtoWE as well as from FtoWE to job satisfaction in mothers and fathers (H2 and H3). The positive link between family meal atmosphere and job satisfaction in fathers expands on studies showing that family satisfaction (Emanuel et al., 2018; Schnettler et al., 2020a; Zhang et al., 2020) and family support (Chan et al., 2020; Lee \& Shin, 2017; Zhang et al., 2018) are associated with positive outcomes in the job domain, enhancing job satisfaction. Given the measure of family meal atmosphere used in this study (Neumark-Sztainer et al., 2000, 2004), the positive association found in fathers between family meals and job satisfaction can be explained as a byproduct of enjoyment and positive family conversations (Jones, 2018; Schnettler et al., 2018a) during family meals. This finding agrees with a positive spillover process i.e., a process in which positive experiences can be transmitted from one domain to another (Bakker \& Demerouti, 2013), from the family to the work domain in the present study. 
Although mothers and fathers did not differ in their scores of family meal atmosphere, the lack of a significant actor effect from the latter to job satisfaction in mothers aligns with findings showing that the potential benefits of family meals may have gender differences. Researchers have reported that mealtime experiences may be different for men and women because of the amount of responsibility that women have in shopping, planning, coordinating, and performing meal-related tasks (Cuevas et al., 2021; Persson Osowski \& Mattsson Sydner, 2019; Rivera \& Giacoman, 2019; Schnettler et al., 2021b). Although in this sample both mothers and fathers reported cooking during the week and on weekends, the amount of time dedicated by mothers was significantly higher than fathers, which reflects the higher burden that mothers experience in cooking activities (Persson Osowski \& Mattsson Sydner, 2019). Nevertheless, there are layers of complexity to this issue. A study conducted in Chile with a sample of dual-earner parents found that fathers' well-being increased when their wives cooked the meals (Schnettler et al., 2020b). The time that mothers dedicate to food-related tasks may thus also be linked to a self-imposed sense of responsibility towards feeding the family, and to positive consequences that mothers may perceive from this higher involvement. Nevertheless, this responsibility for all tasks related to family meals may create a strained family meal atmosphere for mothers.

On this basis, mothers and fathers engage differently with family meals and thus they vary in the resources they obtain (or not) that they can invest in the work domain. Mothers are expected to organize the meal and controlling their children's eating behaviour during the meals (Schnettler et al., 2021b). In contrast, the fathers' involvement in their children's feeding is still low in countries with a traditional family structure, as it occurs in Latin American countries (Schnettler et al., 2021b). For instance, a study with Chilean families showed that fathers vary in their degree of engagement with food-related tasks, from sole financial providers to supporters of their female partner in child-feeding tasks (Hueche et al., 2018). More generally, Musick et al. (2016) have reported that mothers are more likely to use their spare time to respond to childcare demands, while fathers use their spare time to engage in activities that help them improve or maintain their enjoyment and good mood. Taken together, these findings help explain why family meal atmosphere is associated with job satisfaction in fathers, but not in mothers. Although family meals and feeding their children can improve mothers' life satisfaction (Schnettler et al., 2021b), the responsibilities that they face during family meals (Schnettler et al., 2021a) may keep this family activity from providing them with enough personal resources to invest in the work domain.

As it was hypothesised, significant direct actor effects from family meal atmosphere to FtoWE were found for mothers and fathers. As it was the case with fathers above, from the W-HR model and the RGD perspective, these associations may come from family support and related resources provided during a family meal with a pleasant atmosphere (Jones, 2018; Schnettler et al., 2018a). This association between family meal atmosphere and FtoWE may also be explained by the development of other personal resources (i.e., physical and affective) for both parents, even though environmental resources may contribute to enrichment differently by gender (Wayne et al., 2007). The responsibilities that mothers assume for and during family meals may lead them to developing other types of personal resources, compared to fathers, that help them to deal actively and efficiently with home and work tasks (e.g., focus and attention, ten Brummelhuis \& Bakker, 2012). Thus, given mothers and fathers did not differ in their FtoWE scores, we suggest that different contextual or environmental resources allow them to achieve similar levels of FtoWE. However, further research is warranted to identify the specific resources developed by each parent in this enrichment process.

The last actor effect tested in hypothesis 3 showed that FtoWE was positively associated with job satisfaction for both parents, confirming results from earlier studies (Kalliath et al., 2019; Yasir et al., 2019; Yucel, 2020). This finding may be explained by the personal resources developed by fathers and mothers from the contextual resources that involve a positive family mealtime atmosphere. One possible explanation of this resource transference is provided by Kalliath et al. (2019). These authors suggested that when FtoWE occur, individuals experience an accumulation of resources that facilitates job satisfaction, as employees develop positive feelings toward their job. Nevertheless, as parents did not differ in their job satisfaction scores, we suggest that FtoWE has the potential to enhance job satisfaction regardless of the worker's gender, and of the personal resources developed in the process of enrichment.

\section{Partner Effects}

Hypotheses 4, 5 and 6 explored partner effects between family meal atmosphere, FtoWE and job satisfaction for both parents. These hypotheses were not supported. Contrary to expectations (Hobfoll et al., 2018; Orellana et al., 2021a; Peeterset al., 2020; Wayne et al., 2007), the resources acquired by one parent in family meals with a pleasant atmosphere did not cross over to the other parent's job satisfaction nor FtoWE, nor from one parent's FtoWE to the other parent's job satisfaction. The lack of partner effects from one parent's family meal atmosphere to the other parent's job satisfaction can be partially explained by an artifact of the APIM. The lack of actor effects in mothers and the low strength relationship in fathers (i.e., low or nonsignificant actor effects) suggests that partner effects do not 
exist (Garcia et al., 2015). Other dyadic studies have also reported a lack of partner effects for food-related variables in dual-earner couples (Schnettler et al., 2020a), and there is no available evidence of crossover involving WtoFE between members of a couple. The underlying causes of this lack of crossover associations in dual-earner parents should be explored in future studies.

Lastly, regarding the significant effects of the control variables, the higher level of job satisfaction in sel-employed mothers and fathers in comparison to employees is consistent with previous studies showing that high job satisfaction in those self-employed is associated with autonomy at work, flexibility, personal responsibility in task completion, safe working conditions and friendly atmosphere at work (Janicijevic \& Paunović, 2019). However, some of these conditions, such as the flexibility and personal responsibly in task completion, may lead self-employed fathers to stay fewer hours at home and less involved in the domestic and childrearing chores than mothers, which in turn may negatively affect their FtoWE; future research, however, should test this potential explanation. The significant positive of effect of age (Dobrow Riza et al., 2018) and the family SES (Li et al., 2020) on fathers' job satisfaction was also consistent with previous studies. Regarding the positive and significant effect of the number of supper times per week in which both members of the couple ate together on both parents' FtoWE, this result is consistent with previous studies showing a positive association between the frequency of family meals and positive outcomes in mothers and fathers, such as such as lower depression and higher self-esteem in parents (Utter et al., 2018). Our results expand on the knowledge regarding the positive outcomes of frequent family meals by showing a positive influence of the latter on parents' FtoWE, regardless of the parent's gender.

\section{The Mediating Role of Work-to-Family Enrichment}

The last two hypotheses of this study proposed a mediating role of FtoWE between family meal atmosphere and job satisfaction. Hypothesis 7 proposed that FtoWE had a mediating role for both mothers and fathers (actor effects). This expectation was supported, as the atmosphere of family meals and job satisfaction were associated indirectly via FtoWE in individuals regardless of gender. These results are congruent with expectations from the W-HR model (ten Brummelhuis \& Bakker, 2012) and the RGD perspective (Wayne et al., 2007). Namely, a pleasant atmosphere during family meals promotes affective and efficiency developments that can facilitate functioning in the work domain for parents, which in turn can enhance their job satisfaction.

These results also support previous findings regarding a positive association between FtoWE and job satisfaction (Yucel, 2020). Previous studies have provided evidence on the mediating role of FtoWE between family emotional support and firm performance among women running businesses (Neneh, 2017), and between supportive behaviours and balance satisfaction in employees regardless of gender (Wayne et al., 2020). The present study provides new insights into the role of FtoWE in the work-family interface (Chan et al., 2020), showing evidence of its mediation role between a specific family activity and job satisfaction in different-gender dual-earner couples.

Lastly, hypothesis 8 proposed partner effects, so that one parent's FtoWE had a mediating role between the other parent's family meal atmosphere and job satisfaction. This partner effect was not supported (Peeters et al., 2020; Wayne et al., 2007), that is, one parent's transmission of resources from family meals to job satisfaction was not mediated by the other parent's FtoWE. Hypotheses $8 \mathrm{a}$ and $8 \mathrm{~b}$ showed that one parent's perception of family meal atmosphere did not cross over to the other parent's FtoWE, and that one parent's FtoWE was not associated with the other parent's job satisfaction. It may be that parents do acquire resources during family meals, but these resources may not be of use for the other parent's job domain. Hence, FtoWE appears to be an intrasubject mediator regardless of the parent's gender.

\section{Theoretical Implications}

This study expands on the knowledge on the work-family interface for dual-earner parents, and these results have research implications. First, these findings suggest that family events such as (pleasant) family meals may be antecedents of positive work outcomes (i.e., job satisfaction), directly or indirectly through family-to-work enrichment. Future studies should assess the relationship between family meal atmosphere and other positive work outcomes, such as job engagement or commitment, as well as a possible protective effects on negative work outcomes, such as job stress or burnout. A second implication for research is that FtoWE has a similar potential to enhance job satisfaction regardless of the parent's gender, and regardless of the personal resources that may be developed in the process of enrichment. Therefore, further research should assess the enhancing effect of FtoWE on job satisfaction by examining other positive family events in dual-earner families. Lastly, the null effects of FtoWE as one parent's mediator between the other parent's atmosphere of family meals and job satisfaction might imply that FtoWE is an interindividual mediator; both the antecedent (i.e., family meals) and outcome (i.e., job satisfaction) have effects only at the individual level. This finding should be further tested, examining whether other dyadic antecedents and outcomes might show a significant effect, or whether WtoFE is indeed solely a personal experience. Future research should also explore possible moderators of the associations found in this study. For 
instance, both parent's type of employment, the number of family meals per week, the family socioeconomic status and the father's age, given that as control variables they have significantly affected the FtoWE or job satisfaction.

Moreover, new questions arise about these family-to-work relationships in the aftermath of the COVID-19 pandemic. The requirements of working from home, and the additional demands that telework entails, may have had a significant impact in the interplay of family meals and job satisfaction reported in this study. Future research should address these emerging dynamics in the work-family interface to better gauge the needs of parents whose family and work activities and responsibilities have merged in the home space.

\section{Practical Implications}

The results of this study also have practical implications. Campaigns and policies addressing the work-family interface can be informed by the knowledge that pleasant family events, such as family meals, may be a buffer against work demands. Discourses regarding this interface require more emphasis on the dynamics of the family-to-work influence, namely, that family life contributes to the workers' job performance. Identifying those tasks that make up the quality of family life, such as family meals, might help enhance these family-to-work contributions. For instance, a positive engagement with family meals can be improved by and for both parents, for example, via campaigns and policies that promote higher involvement in family life in the realm of public health (e.g., delivering information on the social aspects of food consumption, or on how to involve their children in food tasks) and the workplace (e.g., flexible schedules, measures to avoid work overload).

A second practical implication of these findings is that gender differences continue in the work-family interface experiences: Mothers still carry more demands from the family domain than fathers, especially in lower gender-equality contexts such as Chile (Saieg, 2018). Hence, the above emphasis on the family-to-work influence must recognize that women are likely to face more demands at home than men, while acknowledging that men are also transitioning in their traditional gender roles. Public campaigns and workplace policies can support changes in the homogenization of gender roles in the work and home by promoting training and knowledge that facilitate transferring resources (e.g., time management, moods, motivation) between both domains, and between partners.

\section{Limitations}

The limitations of this study must be considered. The first set of limitations comprise the cross-sectional design and non-probabilistic nature of the sample, which do not allow to establish causality nor to generalize findings. This study addresses actor and partner "effects", in accordance with the APIM language, but the cross-sectional design of this study only allows to establish associations between variables. Cross-sectional designs are considered an important limitation for research on the work-family interface, given that these designs can only uncover correlations between variables and not causal effects (Molina, 2021). Hence, longitudinal research must be conducted to establish causal relationships between the variables under study (Molina, 2021) and to examine families in other life cycle stages. However, conducting longitudinal studies is difficult, as they are expensive and data collection procedures pose practical challenges (Teague et al., 2018). For instance, longitudinal studies require a long-term commitment from the study participants, and attrition (i.e., participants dropping from the study for any reason while it is underway) can threaten the internal and external validity of the findings (Cotter et al., 2005; Teague et al., 2018).

Moreover, data were self-reported, and thus results may have been affected by social desirability. Regarding the sample, the families in this study were representative of the Chilean population in terms of socioeconomic status (AIM, 2016), but not of family composition, as the average number of members (two) and of children (two) per family were higher than the average for a Chilean family (three and one, respectively, INE, 2018). Families were all composed of dual-earner parents with at least one child aged 10 to 15 years. In addition, we did not measure the possible strain that mothers may face during mealtime, the information regarding both parents' job is limited to the type of employment and working hours, and the siblings' age was not asked. Therefore, future studies should consider families in other stages of life, and a measure of the strain faced by mothers compared to fathers. In addition, future research should also explore possible moderators of the associations found in this study, such as the age of the children, the number of adolescent children, the parents' professional fields, among others. As the present study assessed a cross-domain influence of the work-family enrichment model, i.e., FtoWE influencing the work domain, future studies may also assess the mediating role of a within-domain influence, i.e., WtoFE influencing the work domain (Zhang et al., 2018). Lastly, family, cultural and economic factors influence work-family dynamics, and thus cross-cultural studies are required in this field (Molina, 2021). It is recommended that cross-cultural analysis is conducted in other Latin American countries, and other countries with differences in the family structure and gender equality, given that culture affects gendered division of labour, particularly for food-related tasks (Persson Osowski \& Mattsson Sydner, 2019). 


\section{Conclusions}

This study analysed actor and partner effects for the relationships between family meal atmosphere, family-to-workenrichment, and job satisfaction in different-gender dualearner parents with adolescent children. The key finding is the mediating role of family-to-work enrichment, which allows the transmission of resources from one domain to the other by linking positive daily family events to positive job experiences at an individual level. Findings showed that resources acquired by both parents during family meals with a pleasant atmosphere can lead to a greater experience of family-to-work enrichment, which in turn can enhance both parents' job satisfaction. These positive relationships occur regardless of the parent's gender. On the other hand, no partner effects were found, that is, resources acquired by one parent in the family domain did not cross over to the other parent's work domain. Lastly, when examining the mediating role of family-to-work enrichment, gender differences emerged. Family meal atmosphere was associated with job satisfaction directly and indirectly via family-to-workenrichment in fathers, whereas the association between the atmosphere of family meals and job satisfaction was only indirect via family-to-work enrichment in mothers. These findings are a relevant contribution to the literature regarding associations between positive family-related variables (i.e., atmosphere of family meals) and work outcomes (i.e., job satisfaction) for different-gender dual-earner parents. At the same time, our findings provide evidence in favour of the mediating role of family-to-work enrichment to achieve job satisfaction.

Funding This study was funded by Fondecyt Project $n^{\circ} 1190017$.

Data availability The datasets generated during and/or analysed during the current study are available from the corresponding author on reasonable request.

\section{Declarations}

Conflicts of interest/Competing interests The authors have no conflicts of interest to declare that are relevant to the content of this article.

\section{References}

Asociación de Investigadores de Mercado (AIM) (2016). Cómo clasificar los grupos Socioeconómicos en Chile. http://www.iab.cl/ wp-content/uploads/2015/12/Presentaci\%C3\%B3n-final-AIM. pdf. Accessed 23 May 2018.

Agho, A. O., Price, J. L., \& Mueller, C. W. (1992). Discriminant validity of measures of job satisfaction, positive affectivity and negative affectivity. Journal of Occupational and Organizational Psychology, 65(3), 185-195. https://doi.org/10.1111/j.2044-8325. 1992.tb00496.x
Arias, W., Renzo, R., \& Ceballos, K. (2018). Análisis psicométrico de la Escala de Satisfacción Familiar de Wilson y Olson en una muestra de trabajadores de Arequipa. Ciencia y Trabajo, 20(61), 56-60. https://doi.org/10.4067/S0718-24492018000100056

Bahadur, A. G., \& Shakil, J. (2021). An Analysis of Job Satisfaction Determinants of Educators in Low-Performing Schools in Mauritius: A Comparative Study of Private and State Secondary Schools. Journal of Education, 00220574211031979.

Bakker, A. B., \& Demerouti, E. (2013). The spillover-crossover model. In J. G. Grzywacz \& E. Demerouti (Eds.), Current issues in work and organizational psychology. New frontiers in work and family research (pp. 55-70). New York, NY, US: Psychology Press.

Berge, J. M., Miller, J., Watts, A., Larson, N., Loth, K. A., \& NeumarkSztainer, D. (2018). Intergenerational transmission of family meal patterns from adolescence to parenthood: longitudinal associations with parents' dietary intake, weight-related behaviours and psychosocial well-being. Public Health Nutrition, 21(2), 299-308. https://doi.org/10.1017/S1368980017002270

Borodovsky, J. T., Krueger, R. F., Agrawal, A., Elbanna, B., de Looze, M., \& Grucza, R. A. (2021). US trends in adolescent substance use and conduct problems and their relation to trends in unstructured in-person socializing with peers. Journal of Adolescent Health. https://doi.org/10.1016/j.jadohealth.2020.12.144

Brayfield, A. H., \& Rothe, H. F. (1951). An index of job satisfaction. Journal of Applied Psychology, 35(5), 307-311. https://doi.org/ 10.1037/h0055617

Bridges, B. S., \& Owens, T. (2017). Female job satisfaction: can we explain the part-time puzzle? Oxford Economic Papers, 69(3), 782-808. https://doi.org/10.1093/oep/gpw064

Chan, X. W., Kalliath, P., Chan, C., \& Kalliath, T. (2020). How does family support facilitate job satisfaction? Investigating the chain mediating effects of work-family enrichment and job-related wellbeing. Stress and Health, 36(1), 97-104. https://doi.org/10.1002/ smi.2918

Chang, S. J., Van Witteloostuijn, A., \& Eden, L. (2010). From the editors: Common method variance in international business research. Journal of International Business Studies, 41(2), 178-184. https:// doi.org/10.1057/jibs.2009.88

Chen, F. M. (2020). Effects of Daily Parenting Uplifts on Well-being of Mothers with Young Children in Taiwan. Journal of Family Issues, 41(4), 542-561. https://doi.org/10.1177/0192513X19 854120

Claxton, S. E., DeLuca, H. K., \& van Dulmen, M. H. M. (2015). Testing psychometric properties in dyadic data using confirmatory factor analysis: Current practices and recommendations. Testing, Psychometrics, Methodology in Applied Psychology, 22(2), 181-198. https://doi.org/10.4473/TPM22.2.2

Cohen, J. (1988), Statistical Power analysis for the behavioral sciences, Routledge, New York, NY.

Cotter, R. B., Burke, J. D., Loeber, R., \& Mutchka, J. (2005). Predictors of contact difficulty and refusal in a longitudinal study. Criminal Behaviour and Mental Health, 15(2), 126-137. https://doi.org/ $10.1002 / \mathrm{cbm} .46$

Cuevas, C., Herrera, P., Morales, G., Aguayo, L., \& Galvez, P. (2021). Understanding the food-family relationship: A qualitative research in a Chilean low socioeconomic context. Appetite, 156, 104852. https://doi.org/10.1016/j.appet.2020.104852

De Simone, S., Lampis, J., Lasio, D., Serri, F., Cicotto, G., \& Putzu, D. (2014). Influences of work-family interface on job and life satisfaction. Applied Research in Quality of Life, 9(4), 831-861. https://doi.org/10.1007/s11482-013-9272-4

Dobrow Riza, S., Ganzach, Y., \& Liu, Y. (2018). Time and job satisfaction: A longitudinal study of the differential roles of age and tenure. Journal of management, 44(7), 2558-2579. https://doi.org/ $10.1177 / 0149206315624962$ 
Drummond, S., O'Driscoll, M. P., Brough, P., Kalliath, T., Siu, O. L., Timms, C., \& Lo, D. (2017). The relationship of social support with well-being outcomes via work-family conflict: Moderating effects of gender, dependants and nationality. Human Relations, 70(5), 544-565. https://doi.org/10.1177/0018726716662696

Emanuel, F., Molino, M., Presti, A. L., Spagnoli, P., \& Ghislieri, C. (2018). A crossover study from a gender perspective: The relationship between job insecurity, job satisfaction, and partners' family life satisfaction. Frontiers in Psychology, 9, 1481. https:// doi.org/10.3389/fpsyg.2018.01481

Ferrada, L. (2017). Job satisfaction in Chile: geographic determinants and differences. CEPAL Review, 123, 128-145.

Garcia, R. L., Kenny, D. A., \& Ledermann, T. (2015). Moderation in the actor-partner interdependence model. Personal Relationships, 22(1), 8-29. https://doi.org/10.1111/pere.12060

Giray, C., \& Ferguson, G. M. (2018). Say yes to "Sunday Dinner" and no to "Nyam and Scram": Family mealtimes, nutrition, and emotional health among adolescents and mothers in Jamaica. Appetite, 128, 129-137. https://doi.org/10.1016/j.appet.2018. 05.132

Greenhaus, J. H., \& Powell, G. N. (2006). When work and family are allies: A theory of work-family enrichment. Academy of Management Review, 31(1), 72-92. https://doi.org/10.5465/AMR.2006. 19379625

Hobfoll, S. E. (2002). Social and psychological resources and adaptation. Review of General Psychology, 6(4), 307-324. https://doi. org/10.1037/1089-2680.6.4.307

Hobfoll, S. E., Halbesleben, J., Neveu, J. P., \& Westman, M. (2018). Conservation of resources in the organizational context: The reality of resources and their consequences. Annual Review of Organizational Psychology and Organizational Behavior, 5, 103-128. https://doi.org/10.1146/annurev-orgpsych-032117-104640

Hu, L. T., \& Bentler, P. M. (1999). Cutoff criteria for fit indexes in covariance structure analysis: Conventional criteria versus new alternatives. Structural Equation Modeling: A Multidisciplinary Journal, 6(1), 1-55. https://doi.org/10.1080/10705519909540118

Hueche, C., Schnettler, B., \& Denegri, M. (2018). The father's role in food socialization in children: a qualitative study. 30th APS Annual Convention, San Francisco, USA. 24-27 May 2018.

Instituto Nacional de Estadísticas [INE] (2018). Censo de Población $y$ Vivienda 2017. INE. RedAtam Web server. Retrieved from: https://redatam-ine.ine.cl/redbin/RpWebEngine.exe/Portal? BASE=CENSO_2017\&lang=esp Accessed 05 August 2019.

Janicijevic, N., \& Paunović, K. I. (2019). Employee and the selfemployed job satisfaction: Similarities and differences. Management: Journal of Sustainable Business and Management Solutions in Emerging Economies, 24(1), 43-53. https://doi.org/10.7595/ management.fon.2018.0024

Jones, B. L. (2018). Making time for family meals: Parental influences, home eating environments, barriers and protective factors. Physiology \& Behavior, 193, 248-251. https://doi.org/10.1016/j. physbeh.2018.03.035

Kalliath, P., Kalliath, T., Chan, X. W., \& Chan, C. (2019). Linking work-family enrichment to job satisfaction through job well-being and family support: a moderated mediation analysis of social workers across India. The British Journal of Social Work, 49(1), 234-255. https://doi.org/10.1093/bjsw/bcy022

Kenny, D. A., Kashy, D. A., \& Cook, W. L. (2006). Dyadic data analysis. Guilford press.

Kim, S., Chai, D. S., Kim, J., Kim, S., \& Song, Y. (2021). Between Work Conditions and Job Outcomes: Testing a Nomological Network of Life Satisfaction. Applied Research in Quality of Life, 1-25. https://doi.org/10.1007/s11482-021-09971-1

Kuschel, K. (2017). The work-family field: Gaps and missing links as opportunities for future research. Innovar, 27(66), 57-74. https:// doi.org/10.15446/innovar.v27n66.66711
Lau, R. S., \& Cheung, G. W. (2012). Estimating and comparing specific mediation effects in complex latent variable models. Organizational Research Methods, 15(1), 3-16. https://doi.org/10.1177/ 1094428110391673

Ledermann, T., Rudaz, M., \& Grob, A. (2017). Analysis of group composition in multimember multigroup data. Personal Relationships, 24(2), 242-264. https://doi.org/10.1111/pere.12176

Lee, E. S., \& Shin, Y. J. (2017). Social cognitive predictors of Korean secondary school teachers' job and life satisfaction. Journal of Vocational Behavior, 102, 139-150. https://doi.org/10.1016/j.jvb. 2017.07.008

Li, L., Gan, Y., Jiang, H., Yang, Y., Zhou, X., Zheng, Y., et al. (2020). Job satisfaction and its associated factors among general practitioners in China. The Journal of the American Board of Family Medicine, 33(3), 456-459. https://doi.org/10.3122/jabfm.2020. 03.190126

Li, P. F., \& Johnson, L. N. (2018). Couples' depression and relationship satisfaction: examining the moderating effects of demand/ withdraw communication patterns. Journal of Family Therapy, 40, S63-S85. https://doi.org/10.1111/1467-6427.12124

Liu, H., \& Cheung, F. M. (2015). Testing crossover effects in an actorpartner interdependence model among Chinese dual-earner couples. International Journal of Psychology, 50(2), 106-114. https:// doi.org/10.1002/ijop.12070

Marsh, H. W., Hau, K. T., \& Grayson, D. (2005). Goodness of fit evaluation in structural equation modelling. In A. Maydeu-Olivares \& J. McArdle (Eds.), Contemporary Psychometrics (pp. 275-340). Lawrence Erlbaum Associates Publishers.

Matias, M., \& Recharte, J. (2021). Links between work-family conflict, enrichment, and adolescent well-being: Parents' and children's perspectives. Family Relations, 70(3), 840-858. https://doi.org/ 10.1111 /fare. 12453

Molina, J. A. (2021). The Work-Family Conflict: Evidence from the recent decade and lines of future research. Journal of Family and Economic Issues, 42, 4-10. https://doi.org/10.1007/ s10834-020-09700-0

Montero, R., \& Rau, T. (2015). Part-time work, job satisfaction and well-being: Evidence from a developing OECD country. The Journal of Development Studies, 51(4), 370-385. https://doi.org/10. 1080/00220388.2014.963567

Morr Loftus, M. C., \& Droser, V. A. (2020). Parent and Child Experiences of Parental Work-Family Conflict and Satisfaction with Work and Family. Journal of Family Issues, 41(9), 1649-1673. https://doi.org/10.1177/0192513X19895043

Musick, K., Meier, A., \& Flood, S. (2016). How parents fare: Mothers' and fathers' subjective well-being in time with children. American Sociological Review, 81(5), 1069-1095. https://doi.org/10.1177/ 0003122416663917

Neneh, B. N. (2017). Family support and performance of womenowned enterprises: the mediating effect of family-to-work enrichment. The Journal of Entrepreneurship, 26(2), 196-219. https:// doi.org/10.1177/0971355717716762

Neumark-Sztainer, D., Story, M., Ackard, D., Moe, J., \& Perry, C. (2000). Family meals among adolescents. Findings from a pilot study. Journal of Nutrition Education, 32(6), 335-340. https://doi. org/10.1016/S0022-3182(00)70593-0

Neumark-Sztainer, D., Wall, M., Story, M., \& Fulkerson, J. A. (2004). Are family meal patterns associated with disordered eating behaviours among adolescents? Journal of Adolescent Health, 35(5), 350-359. https://doi.org/10.1016/j.jadohealth.2004.01.004

Orellana, L., Schnettler, B., Miranda-Zapata, E., Lobos, G., Lapo, M., Adasme-Berríos, C., \& Hueche, C. (2021a). Resource transmission is not reciprocal: a dyadic analysis of family support, work-life balance, and life satisfaction in dual earner parents with adolescent children. Sex Roles. https://doi.org/10.1007/ s11199-020-01207-0 
Orellana, L., Schnettler, B., Adasme-Berríos, C., Lobos, G., MirandaZapata, E., \& Lapo, M. (2021b). Family profiles based on family life satisfaction in dual-earner households with adolescent children in Chile. Family Process. https://doi.org/10.1111/famp.12714

Paek, S. Y., Nalla, M. K., Lee, J., \& Gurinskaya, A. (2021). The effect of perceived citizen views and supervisor support on Private Security Officers' job satisfaction: the mediating role of selflegitimacy. Security Journal, 1-20.

Pagnan, C. E., Seidel, A., \& MacDermid Wadsworth, S. (2017). I just can't fit it in! Implications of the fit between work and family on health-promoting behaviors. Journal of Family Issues, 38(11), 1577-1603. https://doi.org/10.1177/0192513X16631016

Peeters, M. C., van Steenbergen, E. F., \& Ybema, J. F. (2020). Positive Psychological Micro-Interventions to Improve the Work-Family Interface: Use Your Resources and Count Your Blessings. Frontiers in Psychology, 11, 275. https://doi.org/10.1016/j.jadohealth. 2004.01.004

Persson Osowski, C., \& Mattsson Sydner, Y. (2019). The family meal as an ideal: Children's perceptions of foodwork and commensality in everyday life and feasts. International Journal of Consumer Studies, 43(2), 178-186. https://doi.org/10.1111/ijcs.12495

Riquelme, O., \& Giacoman, C. (2018). La comida en familia: La idealización de un evento social. Revista Chilena de Nutrición, 45(1), 65-70. https://doi.org/10.4067/s0717-75182018000100065

Rivera, V., \& Giacoman, C. (2019). Family meals in Santiago de Chile: An analysis of the role of family, gender and social class in commensality. Appetite, 140, 197-205. https://doi.org/10.1016/j.appet. 2019.05.017

Saadat Abadi Nasab, P., Walters, T., \& Carr, N. (2021). Examining gender roles in family leisure food provisions: a longitudinal photographic analysis. Leisure/Loisir, 1-24. https://doi.org/10.1080/ 14927713.2021.1886868

Rhee, M. K., Park, S. K., \& Lee, C. K. (2020). Pathways from workplace flexibility to turnover intention: Role of work-family conflict, family-work conflict, and job satisfaction. International Journal of Social Welfare, 29(1), 51-61. https://doi.org/10.1111/ ijsw.12382

Saieg, G. (2018). División sexual del trabajo en parejas chilenas con doble ingreso. Master's thesis, Universidad Autónoma de Barcelona.

Schnettler, B., Grunert, K. G., Lobos, G., Miranda-Zapata, E., Denegri, M., Ares, G., \& Hueche, C. (2018a). A latent class analysis of family eating habits in families with adolescents. Appetite, 129, 37-48. https://doi.org/10.1016/j.appet.2018.06.035

Schnettler, B., Denegri, M., Miranda-Zapata, E., \& Saracostti, M. (2018b). Fondecyt Project 1190017, Interrelaciones trabajofamilia-alimentación y satisfacción vital en familias nucleares con dos ingresos parentales e hijos adolescentes, en tres regiones de Chile: un estudio transversal y longitudinal. Conicyt, 2018.

Schnettler, B., Miranda-Zapata, E., Orellana, L., Poblete, H., Lobos, G., Lapo, M., \& Adasme-Berríos, C. (2020a). Domain satisfaction and overall life satisfaction: Testing the spillover-crossover model in Chilean dual-earner couples. International Journal of Environmental Research and Public Health, 17, 7554. https://doi. org/10.3390/ijerph17207554

Schnettler, B., Hueche, C., Andrades, J., Ares, G., Miranda, H., Orellana, L., \& Grunert, K. (2020b). How is satisfaction with foodrelated life conceptualized? A comparison between parents and their adolescent children in dual-headed households. Food Quality and Preference, 86, 104021. https://doi.org/10.1016/j.foodqual. 2020.104021

Schnettler, B., Grunert, K. G., Lobos, G., Miranda-Zapata, E., Denegri, M., \& Hueche, C. (2021a). Exploring relationships between family food behaviour and well-being in single-headed and dualheaded households with adolescent children. Current Psychology, 40(2), 585-600. https://doi.org/10.1007/s1214
Schnettler, B., Rojas, J., Grunert, K. G., Lobos, G., Miranda-Zapata, E., Lapo, M., \& Hueche, C. (2021b). Family and food variables that influence life satisfaction of mother-father-adolescent triads in a South American country. Current Psychology, 40(8), 3747-3764. https://doi.org/10.1007/s12144-019-00328-4

Siu, O. L., Bakker, A. B., Brough, P., Lu, C. Q., Wang, H., Kalliath, T., et al. (2015). A three-wave study of antecedents of workfamily enrichment: The roles of social resources and affect. Stress and Health, 31, 306-314. https://doi.org/10.1002/smi. 2556

Tang, S. W., Siu, O. L., \& Cheung, F. (2014). A study of work-family enrichment among Chinese employees: The mediating role between work support and job satisfaction. Applied Psychology, 63(1), 130-150. https://doi.org/10.1111/j.1464-0597.2012. 00519.x

Teague, S., Youssef, G. J., Macdonald, J. A., Sciberras, E., Shatte, A., Fuller-Tyszkiewicz, M., et al. (2018). Retention strategies in longitudinal cohort studies: a systematic review and metaanalysis. BMC medical Research Methodology, 18(1), 1-22. https://doi.org/10.1186/s12874-018-0586-7

ten Brummelhuis, L. L., \& Bakker, A. B. (2012). A resource perspective on the work-home interface: The work-home resources model. American Psychologist, 67(7), 545. https://doi.org/10. 1037/a0027974

Tisdale, S., \& Pitt-Catshupes, M. (2012). Linking social environments with the well-being of adolescents in dual-earner and single working parent families. Youth \& Society, 44, 118-140. https://doi.org/10.1177/0044118X10396640

Utter, J., Denny, S., Peiris-John, R., Moselen, E., Dyson, B., \& Clark, T. (2017). Family meals and adolescent emotional well-being: findings from a national study. Journal of Nutrition Education and Behavior, 49(1), 67-72. https://doi.org/10.1016/j.jneb.2016. 09.002

Utter, J., Larson, N., Berge, J. M., Eisenberg, M. E., Fulkerson, J. A., \& Neumark-Sztainer, D. (2018). Family meals among parents: Associations with nutritional, social and emotional wellbeing. Preventive Medicine, 113, 7-12. https://doi.org/10.1016/j. ypmed.2018.05.006

Venkatesh, V., Sykes, T., Chan, F., Thong, J., \& Hu, P. (2019). Children's Internet addiction, family-to-work conflict, and job outcomes: A study of parent-child dyads. MIS Quarterly, 43(3), 903-927. https://doi.org/10.25300/MISQ/2019/12338

Vieira, J. M., Marisa, M., Ferreira, T., Lobez, F., \& Matos, P. M. (2016). Parents' work-family experiences and children's problem behaviors: The mediating role of the parent-child relationship. Journal of Family Psychology., 30, 419-430. https://doi. org/10.1037/fam0000189

Wagena, E., \& Geurts, S. (2000). SWING. Ontwikkeling en validering van de" Survey Werk-thuis Interferentie-Nijmegen.". Gedrag \& Gezondheid: Tijdschrift voor Psychologie en Gezondheid.

Wayne, J. H., Grzywacz, J. G., Carlson, D. S., \& Kacmar, K. M. (2007). Work-family facilitation: A theoretical explanation and model of primary antecedents and consequences. Human Resource Management Review, 17(1), 63-76. https://doi.org/10.1016/j.hrmr. 2007.01.002

Wayne, J. H., Matthews, R., Crawford, W., \& Casper, W. J. (2020). Predictors and processes of satisfaction with work-family balance: Examining the role of personal, work, and family resources and conflict and enrichment. Human Resource Management, 59(1), 25-42. https://doi.org/10.1002/hrm.21971

White, H. J., Haycraft, E., Wallis, D. J., Arcelus, J., Leung, N., \& Meyer, C. (2015). Development of the Mealtime Emotions Measure for adolescents (MEM-A): Gender differences in emotional responses to family mealtimes and eating psychopathology. Appetite, 85, 76-83. https://doi.org/10.1016/j.appet.2014.11.011 
World Health Organization (WHO). (2014). Health for the World's Adolescents. A second chance in the second decade. http://www. who.int/adolescent/second-decade. Accessed 11 October 2018.

Yasir, M., Majid, A., \& Khan, N. (2019). Boundary integration, work/ family enrichment and life satisfaction among female nursing staff. Management Research Review, 42(6), 740-759. https://doi. org/10.1108/MRR-01-2018-0041

Yucel, D. (2020). Different Types of Work-Family Balance, Social Support, and Job Satisfaction: A Latent Class Analysis. Applied Research in Quality of Life, 16(3), 1343-1368. https://doi.org/10. 1007/s11482-020-09812-7

Yucel, D., \& Latshaw, B. A. (2020). How Do Mothers' and Fathers' Work-Family Conflict Impact Children's Problem Behaviors? Journal of Family Issues, 42(3), 571-598. https://doi.org/10.1177/ 0192513 X20926209
Zhang, M., Foley, S., Li, H., \& Zhu, J. (2020). Social support, workfamily balance and satisfaction among Chinese middle-and upper-level managers: testing cross-domain and within-domain effects. The international Journal of Human Resource Management, 31(21), 2714-2736. https://doi.org/10.1080/09585192.2018. 1464490

Zhang, Y., Xu, S., Jin, J., \& Ford, M. T. (2018). The within and cross domain effects of work-family enrichment: A meta-analysis. Journal of Vocational Behavior, 104, 210-227. https://doi.org/ 10.1016/j.jvb.2017.11.003

Publisher's note Springer Nature remains neutral with regard to jurisdictional claims in published maps and institutional affiliations. 